\title{
Application of Baranyi function to model the antibacterial properties of solvent extract from Irish York cabbage against food spoilage and pathogenic bacteria
}

\author{
Amit Jaiswal \\ Technological University Dublin, amit.jaiswal@tudublin.ie \\ Nissreen Abu-Ghannam \\ Technological University Dublin, nissreen.abughannam@tudublin.ie \\ Shilpi Gupta \\ Technological University Dublin, shilpi.19may@gmail.com
}

See next page for additional authors

Follow this and additional works at: https://arrow.tudublin.ie/schfsehart

Part of the Life Sciences Commons

\section{Recommended Citation}

Jaiswal, A.K. et al. (2011). Application of Baranyi function to model the antimicrobial properties of solvent extract from Irish York cabbage against food spoilage and pathogenic bacteria. Food Science and Technology International, 17(5), 495-502. DOI 10.1177/1082013210399667

This Article is brought to you for free and open access by the School of Food Science and Environmental Health at ARROW@TU Dublin. It has been accepted for inclusion in Articles by an authorized administrator of ARROW@TU

Dublin. For more information, please contact arrow.admin@tudublin.ie, aisling.coyne@tudublin.ie, gerard.connolly@tudublin.ie.

Funder: Irish Government under the Technological Sector Research Scheme (Strand III) of the National

Development Plan

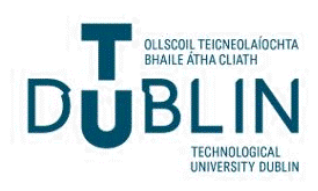




\section{Authors}

Amit Jaiswal, Nissreen Abu-Ghannam, Shilpi Gupta, and Sabrina Cox

This article is available at ARROW@TU Dublin: https://arrow.tudublin.ie/schfsehart/88 


\title{
Application of Baranyi function to model the antibacterial properties of solvent extract from Irish York cabbage against food spoilage and pathogenic bacteria
}

\author{
A.K. Jaiswal, S. Gupta, N. Abu-Ghannam and S. Cox
}

\begin{abstract}
Cabbage is a rich source of a number of bioactive compounds such as flavonoids, glucosinolates and their breakdown products which may have antibacterial, antioxidant and anticancer properties. Outer green leaves of York cabbage were extracted with $60 \%$ methanol, ethanol or acetone. Antibacterial activities of vacuum dried crude extracts were estimated against a number of Gram-positive and Gram-negative food spoilage and food pathogenic bacteria. The crude extracts showed a broad spectrum of antibacterial activities but $60 \%$ methanol extract exhibited the highest antibacterial effect. Complete growth inhibition for Listeria monocytogenes was achieved with an extract concentration of $1.4 \%$, whereas a two-fold concentration was required to achieve a reduction of $75 \%$ and $64 \%$ for Salmonella abony and Pseudomonas aeruginosa, respectively. For Enterococcus faecalis methanolic extract showed a weak inhibition only $(31 \%)$. The lower concentrations of methanolic extract from York cabbage prolonged the lag phase and reduced both the exponential growth rate and final population densities of the culture. Survival of the micro-organisms in presence of methanolic extract was mathematically modeled using Baranyi model equations.
\end{abstract}

\section{Keywords}

Antibacterial activity, York cabbage, Baranyi model, extracts, methanol, modeling

Date received: 28 July 2010; revised: 10 December 2010

\section{INTRODUCTION}

Cabbage (Brassica oleracea) is a leafy garden plant and is among the most important vegetables consumed worldwide due to its availability in local markets and consumer preference. It belongs to the family of Brassicaceae (or Cruciferaceae) along with Collards, Brussels sprouts, Broccoli, Cauliflower and Kale. It is a herbaceous, biennial, dicotyledonous flowering plant distinguished by a short stem upon which crowded a mass of leaves and thought to have originated in Western Europe.

Food Science and Technology International 0(0) 1-8

(C) The Author(s) 2011 Reprints and permissions:

sagepub.co.uk/journalsPermissions.nav

DOI: $10.1177 / 1082013211399667$

fst.sagepub.com

(3)SAGE
Among the cruciferous vegetables, cabbage is the most important dietary vegetable consumed in Europe owing to its availability in local markets, low cost and consumer preference (Kusznierewicz et al., 2008). Cabbage is rich in phytochemicals such as flavonoids and glucosinolates and their hydrolysis products. It is a good source of health promoting compounds that show preventive effect against cancer, atherosclerosis, nephritis and diabetes mellitus (Taveira et al., 2009). Indole3-carbinole, sulforaphane and indole from cabbage

School of Food Science and Environmental Health, College of Science and Health, Dublin Institute of Technology, Cathal Brugha Street, Dublin 1, Ireland.

\section{Corresponding author:}

N. Abu-Ghannam, School of Food Science and Environmental Health, College of Science and Health, Dublin Institute of Technology, Cathal Brugha Street, Dublin 1, Ireland

Email: nissreen.abughannam@dit.ie; shilpi.19may@gmail.com 
help in stabilizing body's antioxidant and detoxification mechanisms that eradicate cancer producing substances (Brooks et al., 2001). Although known for their antioxidant potential some studies are available which report the antibacterial activity in the extracts of many species of Brassicaceae family (Ayaz et al., 2008). Indeed, a few studies have highlighted the potential importance of cabbage as a source of antibacterial substances (Kyung and Flemming, 1994). However, not much data are available which report on the antibacterial kinetics of micro-organisms in the presence of extracts from cabbage.

In recent decades, an increasing tendency has been observed toward the use of natural substances instead of synthetic ones. Also with the increase in the prices of raw materials, the problem of cost benefits for chemical production is becoming more considerable. As a result, great deal of effort is being directed toward identifying low cost natural products that can be safely added to foods for the purpose of inhibiting bacterial growth. In this regard, the extracts from cabbage can be used as a source of antibacterial agents. Glucosinolates and their breakdown products in cabbage have been reported to possess antimicrobial activity (Shofran et al., 1998). However, the yield of desired compound is dependent on the solvent and the method of extraction (Goli et al., 2004). Water, ethanol, methanol and acetone and their aqueous mixtures are commonly used for the extraction of bioactive compounds from plants (Parekh et al., 2005).

Traditional microbial enumeration techniques are time consuming and therefore, mathematical microbial models are used to assess the potential for growth of micro-organisms in foods during processing and storage (Bovil et al., 2001). The empirical sigmoidal type models such as the modified Gompertz and Logistic models or the biological-based Baranyi model have been used for fitting bacterial growth (Huang, 2008). However, data on the use of actual plant extract for inhibiting microbial growth and modeling the resulting kinetics is scarce. Most of the studies done till date use either thermal treatments or purified compounds having antibacterial activity for studying growth inhibition.

There are some reports available wherein the antibacterial effect of solvent extracts from cabbage has been studied on different organisms, but no studies are available wherein the growth inhibition has been modeled. At the same time, there are no studies available which might compare the antibacterial potential of solvent extract from cabbage upon using different extraction solvents. Keeping these facts in mind, this study investigates the comparison of the antibacterial potential of extracts from Irish York cabbage upon using different solvents (ethanol, methanol and acetone) as a natural antibacterial agent for food preservation by examining its effects on the growth kinetics of four common food spoilage and food pathogenic micro-organisms. Thereafter, antibacterial potential of different concentrations of the best solvent were further analyzed by modeling the survival data using the model equations proposed by Baranyi et al. (1993).

\section{MATERIALS AND METHODS \\ Materials}

Plant material. Fresh Irish York cabbage was purchased from a local Supermarket in Dublin in December 2009. Immediately, outer green leaves of cabbage were cut into small pieces and crushed in the presence of liquid nitrogen and stored at $-20{ }^{\circ} \mathrm{C}$ until used.

\section{Methods}

Preparation of extracts. Crushed cabbage (5g) was added to three different flasks and extracted using $60 \%$ ethanol, $60 \%$ methanol or $60 \%$ acetone with 1 min nitrogen flushing. Flasks were kept in a shaking incubator (Innova 42, Mason Technology, Ireland) at $100 \mathrm{rpm}(1.42 \times g)$ and $40{ }^{\circ} \mathrm{C}$ for $2 \mathrm{~h}$ (Figure 1). The infusions were filtered and evaporated to dryness in a multi evaporator (Syncore Polyvap, Mason

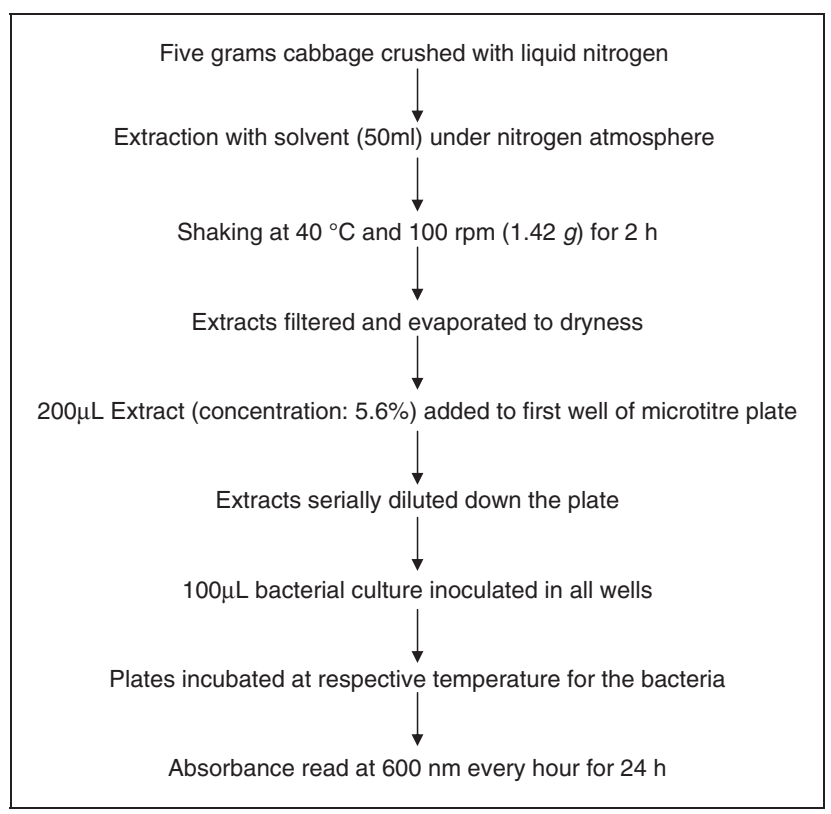

Figure 1. Schematic representation of the experimental protocol. 
Technology, Ireland) and stored at $-20^{\circ} \mathrm{C}$ until used. All the extractions were carried out in triplicates.

Bacterial strains and growth conditions. The bacterial strains used in this study included Gram-negative (Salmonella abony NCTC 6017, Pseudomonas aeruginosa ATCC 27853) and Gram-positive (Listeria monocytogenes ATCC 19115, Enterococcus faecalis ATCC 7080) (Medical Supply Company, Dublin, Ireland). All the cultures were maintained at $-70{ }^{\circ} \mathrm{C}$ in $20 \%$ glycerol stocks and grown in Tryptic Soy Broth (TSB, Scharlau Chemie, Spain) at $37^{\circ} \mathrm{C}$ except $P$. aeruginosa, which was grown at $30{ }^{\circ} \mathrm{C}$ for $18 \mathrm{~h}$ to obtain sub-cultures. To obtain a working concentration, a bacterial suspension was prepared in $\mathrm{NaCl}, 0.85 \%$ (BioMerieux, France) equivalent to McFarland standard of 0.5 with the help of Densimat photometer (BioMerieux, France). Finally, the suspension was diluted with TSB in order to get a concentration of $1 \times 10^{6}$ colony forming units $(\mathrm{CFU}) / \mathrm{mL}$.

Antibacterial activity assay. Antibacterial activity assay of the extracted compound were performed in sterile, round-bottomed 96-well microtiter plates (Sarstedt, Inc, USA). Solvent extract obtained from $5 \mathrm{~g}$ York cabbage was dissolved in $2.5 \mathrm{~mL}$ TSB to get an initial extract concentration of $5.6 \%$, and $200 \mu \mathrm{L}$ from this was added to the first row of each plate. All other wells were filled with $100 \mu \mathrm{L}$ of TSB and $100 \mu \mathrm{L}$ from the first well was serial diluted into two-folds along each column. Finally, $100 \mu \mathrm{L}$ of bacterial suspension containing $1 \times 10^{6} \mathrm{CFU} / \mathrm{mL}$ was added to the wells (effective extract concentration in first well: $2.8 \%$ ). The last column was used for bacterium and media controls and sample blanks were prepared for all the extracts. The plate was incubated in the microtiter reader for $24 \mathrm{~h}$ at respective temperature for each organism. Optical density (OD) measurements were carried out at $0 \mathrm{~h}$ and after incubation for $24 \mathrm{~h}$. Sodium benzoate and sodium nitrite were used as positive controls in concentrations similar to those used for the solvent extracts.

The antibacterial activity of the solvent extracts was expressed in terms of percentage of inhibition and was calculated by the following formula (Casey et al., 2004):

$$
I \%=\frac{\left(C_{24}-C_{0}\right)-\left(T_{24}-T_{0}\right)}{C_{24}-C_{0}} \times 100
$$

where $I$ is the percentage inhibition of growth, $C_{24}$ the blank compensated $\mathrm{OD}_{600}$ of the control of the organism at $24 \mathrm{~h}, C_{0}$ the blank compensated $\mathrm{OD}_{600}$ of the control of the organism at $0 \mathrm{~h}, T_{24}$ the negative control compensated $\mathrm{OD}_{600}$ of the organism in the presence of methanolic extract at $24 \mathrm{~h}$ and $T_{0}$ the negative control compensated $\mathrm{OD}_{600}$ of the organism in the presence of test sample at $0 \mathrm{~h}$.

Relation between turbidity and viable count. In order to convert the OD to $\log \mathrm{CFU} / \mathrm{mL}$, a relationship between $\mathrm{OD}$ at $600 \mathrm{~nm}$ and viable count for all the four bacteria was developed. Bacterial suspension containing $1 \times 10^{6} \mathrm{CFU} / \mathrm{mL}$ was prepared as described in 'Bacterial strains and growth conditions' section. A volume of $200 \mu \mathrm{L}$ from this was dispensed into 50 wells of the 96-well microtiter plate. Every hour, the $\mathrm{OD}$ of the microtiter plate was read and aliquot of $100 \mu \mathrm{L}$ from two wells was transferred into $900 \mu \mathrm{L}$ of maximum recovery diluent (Scharlau Chemie, Barcelona, Spain) to determine the viable count. Spreading was done on Tryptic soy agar (Scharlau Chemie, Barcelona, Spain) plates by taking $100 \mu \mathrm{L}$ of relevant dilution. Plates were incubated at $30{ }^{\circ} \mathrm{C}$ (for $P$. aeruginosa and at $37^{\circ} \mathrm{C}$ for the other three organisms) for $24 \mathrm{~h}$ before determining the number of $\mathrm{CFU} / \mathrm{mL}$. A standard curve $\left(\mathrm{OD}_{600 \mathrm{~nm}}\right.$ vs. $\left.\log \mathrm{CFU} / \mathrm{mL}\right)$ was drawn from the results obtained.

Growth curve. To obtain the growth kinetics of the micro-organisms, microtiter plate based assay as explained in 'Antibacterial activity assay' section was used. Microbial growth kinetics was recorded every hour on a Powerwave microplate spectrophotometer (Powerwave, Biotek) driven by Gen5 reader control and data analysis software. Turbidity was measured as absorbance at $600 \mathrm{~nm}$, with $20 \mathrm{~s}$ agitation before each OD measurement. The OD values were converted to $\log \mathrm{CFU} / \mathrm{mL}$ by the standard curve as described in 'Relation between turbidity and viable count' section.

The survival of the bacteria in the presence of methanolic extract from York cabbage was described by a program implemented in Microsoft excel (DM-Fit; Institute of Food Research, Norwich, UK) which was used to fit the equation of Baranyi et al. (1993). Kinetic parameters such as maximum specific growth rate $\left(\mu_{\mathrm{m}}\right)$, $\log _{10}$ maximum population density $(\gamma)$, lag time $(\lambda)$ and the co-efficient of determination $\left(R^{2}\right)$ for each growth curve were calculated.

Statistical analysis. All experiments were done in triplicate and replicated at least twice. Results are expressed as mean values \pm standard deviation. Analysis of variance (ANOVA) and multiple comparisons (Fisher's least-significant-difference test) were used to evaluate the significant difference among various treatments using the STATGRAPHICS Centurion $\mathrm{XV}$. Differences at $p<0.05$ were considered to be significant. 


\section{RESULTS AND DISCUSSION}

\section{Effect of different solvent extracts on the growth of spoilage and pathogenic organisms}

In the majority of reports on antibacterial activities of vegetables, medicinal plants and spices extracts, bacterial growth inhibiting activities has been investigated by standard disc diffusion assay or well assay (Ayaz et al., 2008). This assay, although good, produces predominantly qualitative results (Casey et al., 2004) and can lead to interpretational problems, including in-growth in the zone of inhibition (Piliouras et al., 2002) and subjectivity associated with visual assessments. This study uses the microtiter plate-based assay which is a robust and quantitative method free from mathematical inaccuracies. At the same time, it can accurately and reproducibly calculate the minimum inhibitory concentration of the bioactive compounds present.

The selection of the pathogenic microbes (L. monocytogenes and $S$. abony) used in this study was made after discussions with the Food Safety Authority of Ireland as these were found to be the most challenging organisms for the safety of food products in Ireland. The other two (E. faecalis and P. aeruginosa) are the most widespread food spoilage micro-organisms. Both these organisms are resistant to the commonly used antibiotics and antibacterial agents.

Since the extraction yield and the extract efficiency varies with the type of solvent system used (Chavan et al., 2001), different concentrations of the extract obtained with $60 \%$ acetone, methanol or ethanol were checked for their antibacterial activity against the four different cultures. A difference in the yield of the extract was observed upon using $60 \%$ methanol $(28 \mathrm{mg} / \mathrm{g}$ cabbage), $60 \%$ ethanol $(32 \mathrm{mg} / \mathrm{g}$ cabbage) and $60 \%$ acetone $(25 \mathrm{mg} / \mathrm{g}$ cabbage). This difference could be due to the increase in the number of soluble components in the mixture, reducing the selectivity and enhancing the yield. Table 1 illustrates the antibacterial activities (percentage inhibition of growth) of the first three dilutions of extract obtained upon using different solvents. Solvents used for extraction had a significant effect on the antibacterial efficacy of Irish York cabbage. Regardless of the organism, 60\% methanol extracts exhibited the highest antibacterial effect (Table 1) than those of $60 \%$ ethanol and $60 \%$ acetone $(p<0.05)$. Resistance to extract was not correlated with taxonomy, since L. monocytogenes (gram-positive) and $S$. abony (gram-negative) were the most sensitive followed by $P$. aeruginosa and $E$. faecalis which was the most resistant. An inhibition of $100 \%$ was achieved against $L$. monocytogenes with extract concentrations of $2.8 \%$ and $1.4 \%$ in methanol, respectively. As the extract concentration was serially diluted, the inactivation effect was seen to reduce.

In case of $S$. abony and $P$. aeruginosa methanolic extracts showed an inhibition in the range 64-74\% and there was reduction of $72 \%$ (S. abony) and $64 \%$ ( $P$. aeruginosa) in the stationary level growth as compared to the control. For the above three organisms, ethanol and acetone extracts, at a concentration of $2.8 \%$, showed weak inhibitions which were in the range 26-39\% only. Enterococcus faecalis was the most resistant among all the organisms and only $26-32 \%$ growth inhibition was achieved using any of the three solvents. Similar results were reported by

Table 1. Antibacterial activities (percentage inhibition of growth) of $60 \%$ ethanol, methanol and acetone extract from cabbage leaves in different concentrations against different organisms

\begin{tabular}{|c|c|c|c|c|}
\hline Organism & Concentrations (\%) & Methanol & Ethanol & Acetone \\
\hline \multirow[t]{3}{*}{ L. monocytogenes } & 2.8 & $100 \pm 0 x$ & $36.7 \pm 3.5 x$ & $39.5 \pm 1.5 x$ \\
\hline & 1.4 & $100 \pm 0 x$ & $30.6 \pm 5.1 x$ & $35.7 \pm 3.5 y$ \\
\hline & 0.7 & $73.4 \pm 6.1 \mathrm{y}$ & $23.7 \pm 3.2 y$ & $27.9 \pm 2.5 z$ \\
\hline \multirow[t]{3}{*}{ S. abony } & 2.8 & $74.7 \pm 4.4 x$ & $34.9 \pm 2.2 x$ & $26.1 \pm 2.7 x$ \\
\hline & 1.4 & $48.2 \pm 6.9 y$ & $15.3 \pm 1.4 y$ & $21.7 \pm 4.2 y$ \\
\hline & 0.7 & $23.3 \pm 4.3 z$ & ND & ND \\
\hline \multirow[t]{3}{*}{$P$. aeruginosa } & 2.8 & $64.2 \pm 6.4 x$ & $35.3 \pm 3.6 x$ & $30.5 \pm 3.6 x$ \\
\hline & 1.4 & $49.2 \pm 6.0 y$ & $5.7 \pm 0.7 y$ & $3.6 \pm 1.3 y$ \\
\hline & 0.7 & $31.6 \pm 5.8 z$ & $2.55 \pm 4.9 y$ & $2.80 \pm 3.1 y$ \\
\hline \multirow[t]{3}{*}{ E. faecalis } & 2.8 & $30.9 \pm 3.75 x$ & $32.2 \pm 3.24 x$ & $25.8 \pm 1.10 x$ \\
\hline & 1.4 & $26.1 \pm 3.19 x$ & $25.6 \pm 3.96 y$ & $13.8 \pm 2.59 y$ \\
\hline & 0.7 & $12 \pm 4.82 y$ & $23.4 \pm 2.72 y$ & $9.71 \pm 1.88 z$ \\
\hline
\end{tabular}

ND: not detected. All the values are means \pm SD of three experiments in duplicate.

Means within each column bearing the different letters are significantly different $(p<0.05)$. 


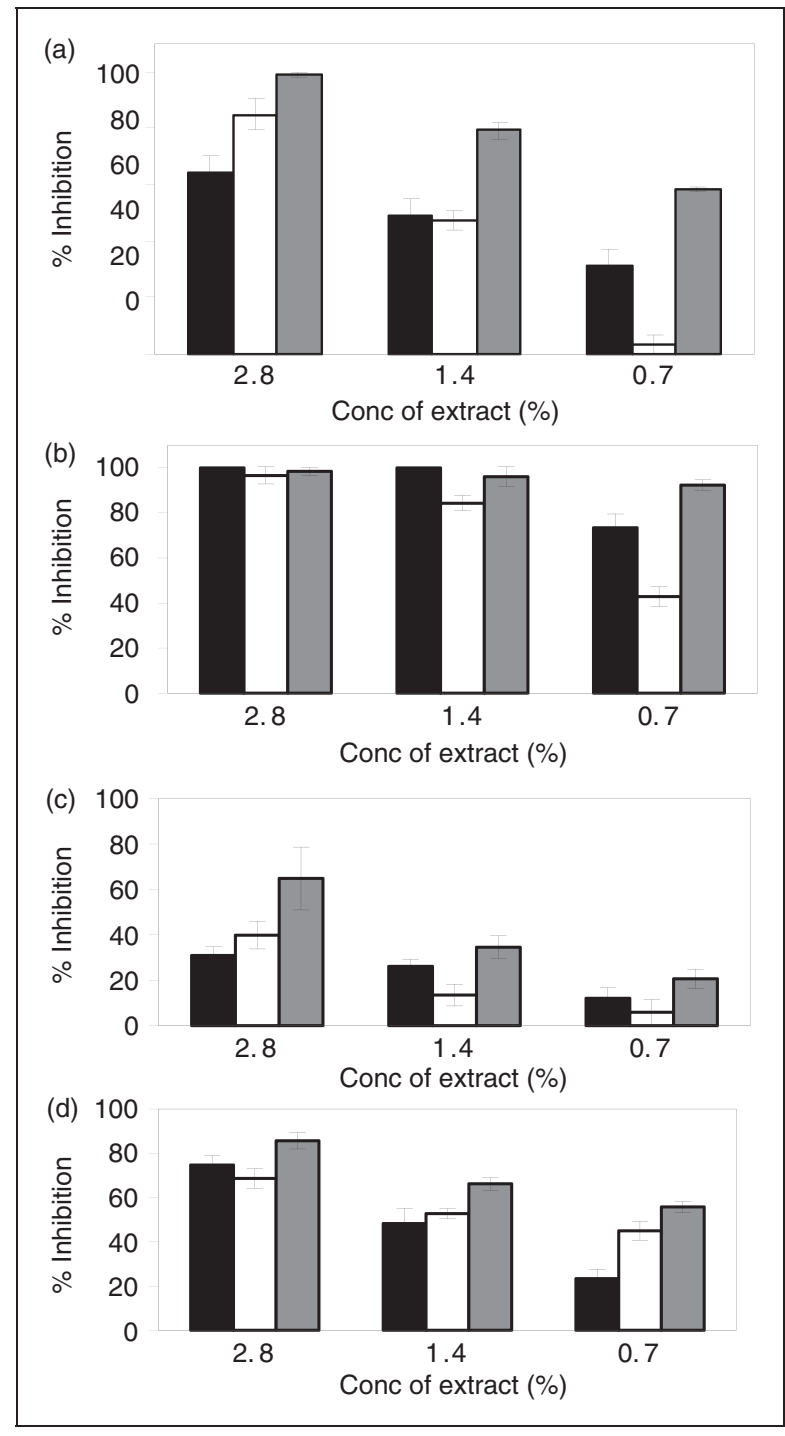

Figure 2. Comparative study of antibacterial activities of the first three dilutions for cabbage, extracted with $60 \%$ methanol with sodium benzoate and sodium nitrite against: (a) P. aeruginosa, (b) L. monocytogenes, (c) E. faecalis and (d) S. abony.: $60 \%$ methanol; sodium benzoate; sodium nitrite (all the values are means \pm SD of three independent experiments in duplicate).

Ayaz et al. (2008), where it was observed that solvent extracts from Kale were not effective against $E$. faecalis.

The aim of extracting antibacterial compounds from their plant sources is to release the desired compounds either through rupturing plant tissue or through a process of diffusion. Chemical characteristics of the solvent and the structure and composition of the compound insures that each material solvent system shows different behavior. The result of this study showed that methanol extracts have highest antibacterial properties compared to ethanol and acetone extracts. These observations may be attributed to three reasons: first, the nature of biologically active components whose activity can be enhanced in the presence of methanol; second, the stronger extraction capacity of methanol could have extracted more of active constituents responsible for antibacterial activity and third, the antibacterial compounds belongs to the family of polyphenols which have increased aqueous alcoholic solubility. There are reports in the literature that methanol is a better solvent for consistent extraction of antibacterial substances from medicinal plants (Ozturk and Ercisli, 2006).

Antibacterial activities of $60 \%$ methanol extract were also compared with positive controls (Figure 2), such as sodium benzoate and sodium nitrite. Sodium benzoate is a common food preservative used in fruit products like jams, beverages, salads, pie, pastry fillings, icings and olives, whereas sodium nitrite is used in ready-to-eat meat products and fish. According to the European Food Directive 95/2/EC (European Parliament and Council Directive No 95/2/EC) on 'Food Additives other than Colours and Sweeteners,' the maximum permitted level of sodium benzoate is $0.15-2 \mathrm{~g} / \mathrm{kg}$ depending on the food product. Sodium nitrite is permitted at $0.3 \mathrm{~g} / \mathrm{kg}$ in meat products. A $60 \%$ methanolic extract showed significantly higher inhibition (100\%) against L. monocytogenes (Figure 2b) compared to sodium benzoate $(84.4 \%)$ and sodium nitrite $(96 \%)$ upon using similar concentrations of the methanolic extracts or the controls $(2.8 \%)(p<0.05)$. Even S. abony (Figure 2d) was inhibited to a higher extent $(74.7 \%)$ with $60 \%$ methanol compared to sodium benzoate $(68.6 \%)$ when the methanolic extracts or the positive control was added at a concentration of $2.8 \%$. The concentration of methanolic extract used in this study is higher than the values permitted value for sodium benzoate in foods. Nonetheless, even at those concentrations, the methanolic extracts were found to be more potent than the positive controls. However, further studies will be carried out in our laboratories to purify these extracts so that a concentrated purified compound having antimicrobial activity at a much lesser concentration could be obtained and used as a nutraceutical in the food industry. Moreover, this study clearly indicated that methanolic extracts were the most potent among the various solvent extracts. Thus, it will be important to insure with proper chromatographic studies that no traces of methanol are left in the extract before it is used for any food grade application.

A positive finding from these results was that the methanolic extracts were effective against the food pathogen L. monocytogenes, which accounts for the highest hospitalization rate $(90 \%)$ and the second highest fatality rate $(20 \%)$ among all food borne human pathogens. Like all food borne pathogens, Listeria is easily killed by thermal treatment but the post-processing environment in the preparation of ready-to-eat 

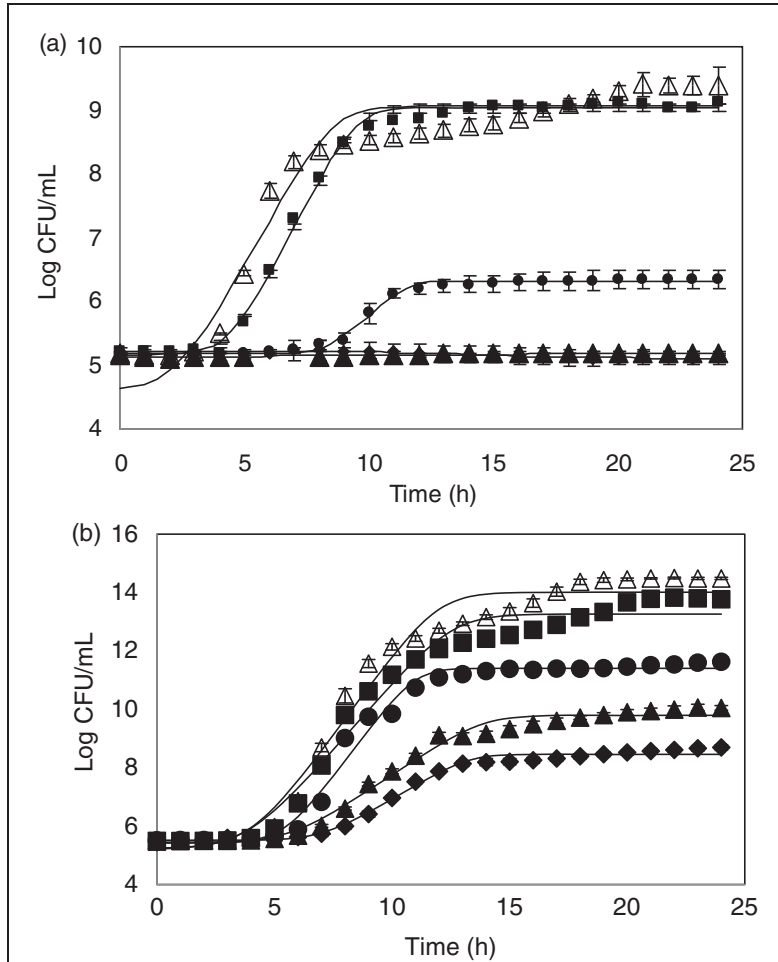

(c)

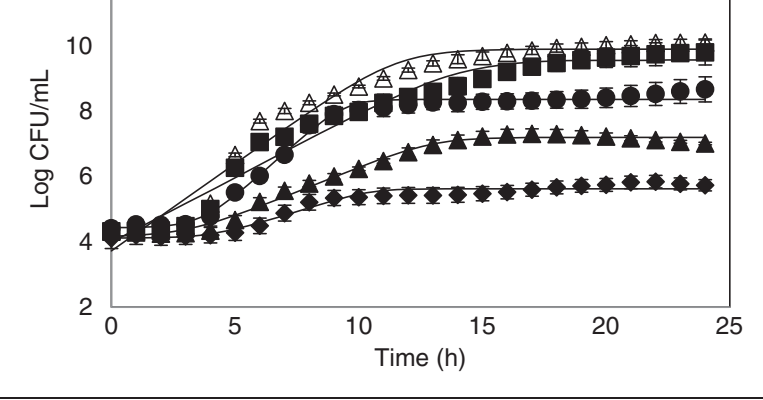

Figure 3. Growth kinetics of bacteria in the presence of different concentrations of methanolic extracts from York cabbage (a) L. monocytogenes, (b) P. aeruginosa and (c) $S$. abony. Different concentrations of extract used. $(\downarrow): 2.8 \%$; (A) $1.4 \%$; (•) $07 \%$; (घ) $0.35 \%$ and $(\triangle)$ : $0 \%$.

foods is conducive to its growth. Therefore, the present finding brings out a new insight toward the development of natural antibacterial agents against Listeria from Irish York cabbage.

\section{Effect of addition of extract on growth kinetics}

From the above results, it became clear that methanolic extracts had a strong antibacterial effect on $L$. monocytogenes and a moderate effect on $S$. abony and $P$. aeruginosa. However, it was important to study the effect of extract on the growth kinetics of the bacteria in order to ascertain its effect on the maximum specific growth rate and the lag phase of the bacterial strains.
Thus, survival data were mathematically modeled using the Baranyi model equations. Since the yield of the methanolic extract was only $28 \mathrm{mg} / \mathrm{g}$ cabbage, the kinetics of growth inhibition was checked by measuring the OD by a microtiter plate-based assay rather than by the conventional spread plate method. The OD of the culture was converted to $\log \mathrm{CFU} / \mathrm{mL}$ by the standard curve as explained in 'Relation between turbidity and viable count' section.

As expected, control samples showed a rapid and prolific growth, as the population was 9.9, 10.1, 14.4 and $14.5 \log \mathrm{CFU} / \mathrm{mL}$ after $24 \mathrm{~h}$ for L. monocytogenes, $S$. abony, E. faecalis and $P$. aeruginosa, respectively (Figure 3). The incorporation of methanolic extracts from York cabbage resulted in variable levels of inhibition in the growth of the different organisms. Figure 3 shows the influence of the crude extracts obtained from cabbage on the four organisms. The extract had an antagonizing effect on the food spoilage and pathogens studied, showing a remarkable dose-response relationship with an increase of the lag phase duration and decrease of the maximum specific growth rate. In addition, a reduction in the maximum number attained or complete suppression of growth was observed. Complete inactivation of L. monocytogenes in presence of methanolic extract from York cabbage was seen at the two highest extract concentrations $(2.8 \%$ and $1.4 \%)$ used (Figure 3a). Although, the addition of extracts at a concentration of $0.7 \%$ did not result in a complete killing of bacteria, but the growth kinetics was significantly altered. A lag phase much longer than the control was observed and the growth rate was highly subdued. At the same time, there was a reduction of $76 \%$ in the stationary level growth as compared to the control. In case of $P$. aeruginosa (Figure 3b) and $S$. abony (Figure 3c), addition of $2.8 \%$ extract resulted in an extension of lag phase. The extract was least effective against $E$. faecalis and a very minimal extension in lag phase was observed (data not shown).

The Baranyi model equations were used to analyze the delay or inhibition of growth against the different organisms in order to determine the parameters for the model. Since, the methanolic extract was not having much effect on E. faecalis, it was not considered for kinetics analysis. A comparison of the model simulated and experimental data for L. monocytogenes, $P$. aeruginosa and S. abony is depicted in Figure 3. The Baranyi model was capable of fitting the experimental data very reasonably and produced curves with an $R^{2}$ value ranging from 0.875 to 0.996 . The model kinetic parameters such as the $\lambda$ and $\mu$ estimated using the experimental data with the Baranyi model are summarized in Table 2. ANOVA indicated that the maximum specific growth rate was significantly reduced $(p<0.05)$ with increasing extract concentration (Table 2). 
Jaiswal et al.

Table 2. Value of model parameters (lag phase and maximum specific growth rate) for fitting of Baranyi model

\begin{tabular}{llcr}
\hline Organism & Concentrations (\%) & Lag $(\mathrm{h})$ & $\mu_{\mathrm{m}}\left(\mathrm{h}^{-1}\right)$ \\
\hline P. aeruginosa & 2.8 & 7.01 & 0.469 \\
& 1.4 & 5.62 & 0.533 \\
& 0.7 & 5.4 & 1.06 \\
& 0.35 & 3.83 & 0.92 \\
S. abony & Control & 3.9 & 1.1 \\
& 2.8 & 4.065 & 0.24 \\
& 1.4 & 3.07 & 0.31 \\
& 0.7 & 3.6 & - \\
L. monocytogenes & 0.35 & - & 0.4 \\
& Control & - & 0.53 \\
& 2.8 & 11.3 & -0.014 \\
& 1.4 & - & 0.003 \\
& 0.7 & 8.1 & 0.316 \\
& 0.35 & 4.3 & 0.746 \\
\hline
\end{tabular}

The prominent effect of the extract was an increase in the lag phase duration. A delay in, or inhibition of, microbial growth is particularly useful in terms of food safety. The extension of the lag phase is probably the most widely used parameter to describe the inhibitory effects of antibacterial compounds and a slight delay in the lag phase may have an important influence on the shelf-life of food products. Thus, the prolonging of lag phase could be used as an appropriate index for evaluation of the activity of the antibacterial compounds. In this study, a linear positive correlation was obtained between the lag phase and the concentration of methanolic extract for L. monocytogenes, $P$. aeruginosa and $S$. abony (Figure 4a). The methanolic extracts were potent even at an extract concentration as low as $0.7 \%$ resulting in 1.3 and 3.7 fold increase in the lag phase of $P$. aeruginosa and L. monocytogenes, respectively. The extracts had also an equally inhibitory effect on the maximum specific growth rate of the cells (Figure 4b). In case of $P$. aeruginosa and $S$. abony, although the addition of $2.8 \%$ did not result in inactivation but there was $57 \%$ and $55 \%$ reduction in the maximum specific growth rate of the cells as compared to the control. Due to this, there was only 1.6 and $3 \log$ increase in the cell number at the end of $24 \mathrm{~h}$ as compared to 6 and 9log increase in the cell number in the controls of $S$. abony and $P$. aeruginosa, respectively. Thus, it is possible that the addition of extracts at a concentration of $2.8 \%$ probably caused some injury to the cells, which resulted in the inability of the cells to recover and grow to levels which were achieved in the absence of the extract.

The extracts from York cabbage showed inhibitory effects against L. monocytogenes and an ability of lag phase extension for the other organisms tested in this

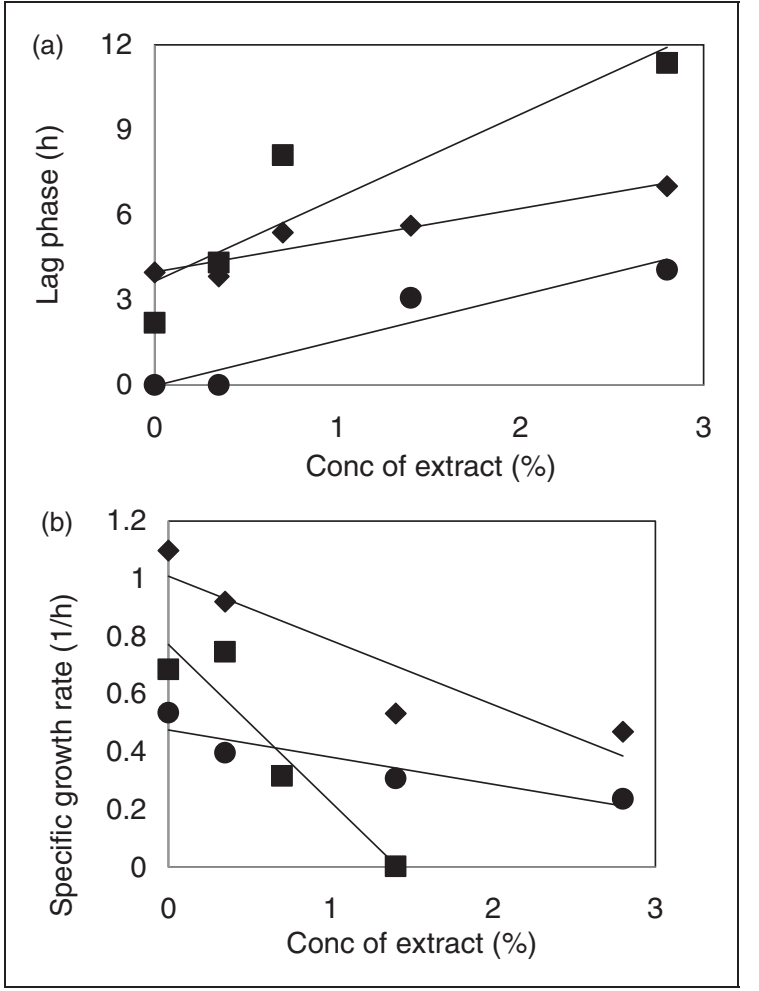

Figure 4. Relation between concentration of methanolic extract from York cabbage against the three different organisms (घ): L. monocytogens $R^{2}=0.8327 ;(\bullet)$ : S. abony $R^{2}=0.8999,(\checkmark)$ : $P$. aeruginosa $\left.R^{2}=0.9115\right)$ with the (a) lag phase and (b): $(\mathbf{\square})$ : L. monocytogens $R^{2}=0.8881 ;(\bullet): S$. abony $R^{2}=0.8481$, $(\diamond)$ : $P$. aeruginosa $R^{2}=0.8467$ with maximum specific growth rate. 
study. Thus, the addition of extracts from York cabbage has the potential of imparting microbiological safety to food products in addition to enriching foods with bioactives (Brooks et al., 2001) such as antioxidants which have a role in preventing oxidative spoilage.

\section{CONCLUSIONS}

This study demonstrates that conventional organic solvent extracts of Irish York cabbage have significant antibacterial activity against food spoilage and food pathogenic bacteria $L$. monocytogenes and $P$. aeruginosa. In all, 60\% methanolic extract had higher antibacterial activity in the case of $L$. monocytogenes and $S$. abony as compared to typical food preservatives such as sodium benzoate and sodium nitrite. Extracts obtained upon the use of methanol showed higher antibacterial activity compared to other solvent extract tested hence, methanol was the best solvent for the extraction of antibacterial compounds from cabbage. The present findings appear useful in leading to further experiments on the identification, isolation and characterization of specific compounds that are responsible for antibacterial activity of Irish York cabbage. These results might help in the development or modification of processing conditions, or the implementation of new preservation agents to complement those already employed in food preservation and safety.

\section{ACKNOWLEDGMENTS}

The authors acknowledge funding from the Irish Government under the Technological Sector Research Scheme (Strand III) of the National Development Plan.

\section{REFERENCES}

Ayaz FA, Ayaz SH, Karaoglu SA, Gruz J, Valentova K, Ulrichova J, et al. (2008). Phenolic acid contents of kale (Brassica oleracea L. var. acephala DC.) extracts and their antioxidant and antibacterial activities. Food Chemistry 107(1): 19-25.

Baranyi J, Roberts TA and McClure P. (1993). A non-autonomous differential equation to model bacterial growth. Food Microbiology 10(1): 43-59.

Bovil RA, Bew J and Barranyi J. (2001). Measurements and predictions of growth for Listeria monocytogenes and Salmonella during fluctuating temperature. II. Rapidly changing temperatures. International Journal of Food Microbiology 67(1-2): 131-137.

Brooks JD, Paton VG and Vidanes G. (2001). Potent induction of phase 2 enzymes in human prostate cells by sulforaphane. Cancer Epidemiology Biomarkers and Prevention 10(9): 949-954.

Casey JT, O'Cleirigh C, Walsh PK and O'Shea DG. (2004). Development of a robust microtiter plate-based assay method for assessment of bioactivity. Journal of Microbiological Methods 58(3): 327-334.

Chavan UD, Shahidi F and Naczk M. (2001). Extraction of condensed tannins from beach pea (Lathyrus maritimus L.) as affected by different solvents. Food Chemistry 75(4): 509-512.

European Parliament and Council Directive No. 95/2/EC (OJ L61, p1, 18/03/1995) of 20 February 1995 on Food Additives other than Colours and Sweeteners.

Goli AH, Barzegar M and Sahari MA. (2004). Antioxidant activity and total phenolic compounds of pistachio (Pistachia vera) hull extracts. Food Chemistry 92(3): 521-525.

Huang L. (2008). Growth kinetics of Listeria monocytogenes in broth and beef frankfurters - determination of lag phase duration and exponential growth rate under isothermal conditions. Journal of Food Science 73(5): E235-E242.

Kusznierewicz B, Bartoszek A, Wolska L, Drzewiecki J, Gorinstein S and Namieśnik J. (2008). Partial characterization of white cabbages (Brassica oleracea var. capitataf. alba) from different regions by glucosinolates, bioactive compounds, total antioxidant activities and proteins. LWT-Food Science and Technology 41(1): 1-9.

Kyung KH and Fleming HP. (1994). S-Methyl-L-Cystine sulfoxide as the precursor of methyl methanethiosulfinate, the principal antibacterial compound in cabbage. Journal of Food Science 59(2): 350-355.

Ozturk S and Ercisli S. (2006). The chemical composition of essential oil and in vitro antibacterial activities of essential oil and methanol extract of Ziziphora persica bunge. Journal of Ethnopharmacology 106(3): 372-376.

Parekh J, Jadeja D and Chanda S. (2005). Efficacy of aqueous and methanol extracts of some medicinal plants for potential antibacterial activity. Turkish Journal of Biology 29: 203-210.

Piliouras P, Ulett GC, Ashhusrt-Smith C, Hirst RG and Norton RE. (2002). A comparison of antibiotic susceptibility testing methods for cotrimoxazole with Bukholderia pseudomallei. International Journal of Antimicrobial Agents 19(5): 427-429.

Shofran BG, Purrington ST, Briedt $F$ and Fleming HP. (1998). Antimicrobial properties of sinigrin and its hydrolysis products. Journal of Food Science 63(4): 621-624.

Taveira M, Pereira DM, Sousa C, Ferreres F, Andrade PB, Martins A, et al. (2009). In vitro cultures of Brassica oleracea 1 . var. costata dc: potential plant bioreactor for antioxidant phenolic compounds. Journal of Agricultural and Food Chemistry 57(4): 1247-1252. 